\title{
CHRONIC DIRECT RENIN INHIBITION WITH ALISKIREN PREVENTS THE DEVELOPMENT OF HYPERTENSION IN CYP1A1-REN2 TRANSGENIC RATS WITH INDUCIBLE ANG II- DEPENDENT HYPERTENSION
}

\author{
Lily Huang, BS, Catherine G. Howard, BS, and Kenneth D. Mitchell, PhD \\ Department of Physiology, Tulane Hypertension and Renal Center of Excellence, Tulane \\ University School of Medicine, New Orleans, LA.
}

\begin{abstract}
Introduction-The present study was performed to determine if chronic direct renin inhibition can prevent the development of slowly progressive ANG II-dependent hypertension and the associated derangements in renal function in Cyp1a1-Ren2 transgenic rats with inducible expression of the Ren 2 gene.

Methods-Male Cyp1a1-Ren2 rats $(\mathrm{n}=6)$ were fed a normal diet containing 0.15\% indole-3carbinol (I3C) for 16 days to induce slowly progressive ANG II-dependent hypertension. Conscious systolic blood pressure (SBP) was measured daily using tail-cuff plethysmography. The rats were then anesthetized with pentobarbital sodium and surgically prepared for the measurement of mean arterial pressure (MAP) and renal hemodynamics and excretory function.
\end{abstract}

\begin{abstract}
Results-In rats induced with I3C, SBP increased by day $3(130 \pm 7$ to $160 \pm 5 \mathrm{mmHg}, \mathrm{P}<0.01)$ and continued to increase to $191 \pm 6 \mathrm{mmHg}(\mathrm{P}<0.001)$ by day 16 . In a separate group of rats $(\mathrm{n}=6)$, chronic administration of the direct renin inhibitor, aliskiren $(30 \mathrm{mg} / \mathrm{kg} / \mathrm{day}, \mathrm{sc})$, prevented the development of hypertension $(113 \pm 5$ vs. $114 \pm 5 \mathrm{mmHg}, \mathrm{NS})$. Rats treated with aliskiren exhibited significantly lower MAP (138 \pm 4 vs. $201 \pm 6 \mathrm{mmHg}, \mathrm{P}<0.001)$, RVR $(23 \pm 4$ vs. $38 \pm 3 \mathrm{mmHg} / \mathrm{ml} /$ min.g, $\mathrm{P}<0.01$ ), urine flow (17.6 \pm 1.4 vs. $25.1 \pm 2.9 \mu \mathrm{L} / \mathrm{min}, \mathrm{P}<0.05)$, and urinary sodium excretion $(1.11 \pm 0.32$ vs. $2.35 \pm 0.28 \mu \mathrm{Eq} / \mathrm{min}, \mathrm{P}<0.05)$, and higher $\mathrm{RPF}$ ( $4.22 \pm 0.23$ vs. $2.56 \pm 0.21 \mathrm{ml} / \mathrm{min} . \mathrm{g}$, $\mathrm{P}<0.01)$ and GFR $(1.19 \pm 0.07$ vs. $0.78 \pm 0.08 \mathrm{ml} / \mathrm{min} . \mathrm{g}, \mathrm{P}<0.01)$, compared with induced rats not treated chronically with aliskiren.
\end{abstract}

Conclusions-The present findings demonstrate that chronic direct renin inhibition with aliskiren prevents the development of ANG II-dependent hypertension and the associated derangements in renal hemodynamics and excretory function in Cyp1a1-Ren2 transgenic rats.

\section{Keywords}

kidney; renin-angiotensin system; renin inhibitor; renal hemodynamics; sodium excretion

\footnotetext{
Address correspondence to: Kenneth D. Mitchell, PhD, FAHA, FASN, Department of Physiology, Tulane University Health Sciences Center, 1430 Tulane Avenue, SL39, New Orleans, LA 70112, Phone: 504-988-2593, Fax: 504-988-2675, kdmitch@tulane.edu. Publisher's Disclaimer: This is a PDF file of an unedited manuscript that has been accepted for publication. As a service to our customers we are providing this early version of the manuscript. The manuscript will undergo copyediting, typesetting, and review of the resulting proof before it is published in its final citable form. Please note that during the production process errors may be discovered which could affect the content, and all legal disclaimers that apply to the journal pertain.
} 


\section{Introduction}

The Cyp1a1Ren2 transgenic rat line was created by inserting the mouse Ren2 renin gene, fused to an $11.5 \mathrm{~kb}$ fragment of the cytochrome $\mathrm{P} 450$ 1a1 promoter, into a neutral genomic site on the Y chromosome of the Fischer 344 rat. ${ }^{1}$ Cyp1a1, which catalyzes the oxidation of a wide range of endogenous lipophilic compounds and xenobiotics ${ }^{2-4}$, is not constitutively expressed but is highly inducible on exposure to various aryl hydrocarbons such as indole-3carbinol (I3C). ${ }^{2-8}$ Induction of Cyp1a1 is mediated by the aryl hydrocarbon receptor, which is a basic helix-loop-helix-transcription factor that binds to specific DNA elements in the Cyp1a1 promoter. ${ }^{2,4,9}$ Rats transgenic for the Cyp1a1-Ren2 construct do not constitutively express the Ren 2 renin gene. Rather, the Ren 2 gene is expressed, primarily in the liver, only on induction of the Cyp1a1 promoter by dietary administration of aryl hydrocarbons such as I3C. ${ }^{1}$ Previous studies have demonstrated that chronic dietary administration of I3C increases blood pressure in a dose-dependent fashion. ${ }^{1,10}$ At a dose of $0.15 \%(w / w)$, dietary I3C administration leads to hypertension that develops gradually over the course of 14-16 days. ${ }^{10,11}$ In contrast, at a higher dose of $0.3 \%(\mathrm{w} / \mathrm{w})$, dietary I3C induces malignant hypertension characterized by rapid development of hypertension, severe loss of body weight, lethargy and piloerection. ${ }^{10,12,13}$ Additionally, dietary I3C increases plasma renin activity (PRA) and plasma angiotensin (ANG) II levels in a dose dependent manner. ${ }^{10}$

Recent investigations showed that $\mathrm{AT}_{1}$ receptor blockade both prevents and treats the increase in blood pressure in Cyp1a1-Ren2 rats induced with $0.3 \%$ I3C. ${ }^{14,15,16}$ These findings have strongly suggested that the hypertension Cyp1a1-Ren2 animals induced with I3C has been mediated via an ANG II dependent mechanism. However, little information is available regarding the blood pressure and renal effects of the new pharmacologic targets to the renin-angiotensin system such as aliskiren, the first direct renin inhibitor in the US market, in slowly progressive forms of ANG-II dependent hypertension. Aliskiren binds to the $\mathrm{S} 3^{\mathrm{bp}}$ binding pocket of renin, its active site, thereby preventing the conversion of angiotensinogen to ANG I. ${ }^{17,18}$ Although originally designed to bind to human renin, animal studies have shown aliskiren binds mouse renin effectively in models that upregulate mouse renin. ${ }^{18}$ Human clinical trials have shown that aliskiren suppresses both PRA and hypertension. Chronic administration of aliskiren in TGR(mRen2)27 rats that constitutively express the mouse Ren 2 renin gene has shown that aliskiren suppresses hypertension, reduces renal and cardiac pathologies associated with increased blood pressure and prevents the increases in both kidney and plasma ANG II levels. ${ }^{19,20}$ Acute administration of aliskiren in the Cyp1a1-Ren2 transgenic rat model with inducible malignant hypertension demonstrated that aliskiren normalizes mean arterial pressure (MAP) and renal plasma flow (RPF) without altering glomerular filtration rate (GFR). ${ }^{21}$ However, little is known about the effects of chronic administration of a direct renin inhibitor on the prevention of blood pressure and the associated derangements in renal hemodynamics and sodium excretory function in slowly progressive form of ANG II-dependent hypertension. This study was performed to address the hypothesis that chronic direct renin inhibition with aliskiren prevents increases in arterial blood pressure and associated derangements in renal hemodynamics and sodium excretory function in Cyp1a1-Ren2 transgenic rats with slowly progressive ANG II-dependent hypertension.

\section{Methods}

The experimental procedures in this study conform to the National Institutes of Health Guide for the Care and Use of Laboratory Animals and were approved by the Institutional Animal Care and Use Committee of Tulane University Health Sciences Center. Experiments were performed on adult male transgenic rats [TGR(Cyp1a1Ren2)] with inducible expression of the mouse Ren 2 renin gene. ${ }^{1}$ All transgenic rats used in the present study were 
adult male Cyp1a1-Ren2 transgenic rats (249-280 g) bred at Tulane University School of Medicine from stock animals supplied by Harlan UK Limited, Bicester, UK. The experimental animals were divided into 3 groups. Group 1 (noninduced; $n=6$ ) were maintained on a normal, non-I3C rat diet (diet TD 99414; Harlan-Teklad, Madison, WI) for 16 days. Group $2(0.15 \%$ I3C; $n=6)$ Cyp1a1-Ren2 rats were fed a normal diet containing $0.15 \%$ I3C for 16 days to induce slowly progressive ANG II-dependent hypertension. Group 3 (I3C+Aliskiren; n=6) Cyp1a1-Ren2 rats were implanted with an Alzet 2ML4 osmotic minipumps administering aliskiren ( $30 \mathrm{mg} / \mathrm{kg} / \mathrm{d}$, subcutaneously) 3 days prior to initiating dietary administration of $0.15 \% \mathrm{I}$ C. Sham surgeries were performed on groups 1 and groups 2 to control for the minor surgical trauma experienced by group 3 . The dose of aliskiren used in this study was chosen on the basis of the previous observation that chronic administration of this dose of aliskiren elicited a pronounced and prolonged decrease in blood pressure in hypertensive TGR(mRen2)27 transgenic rats, which constitutively express high levels of the mouse Ren 2 renin gene. ${ }^{22}$ They were fed a normal diet containing $0.15 \%$ I3C for 16 days. The rats were allowed free access to food and tap water until day 16.

Measurement of conscious systolic blood pressure (SBP) was obtained in conscious rats using tail-cuff plethysmography (Model 6R22931, IITC Life Science; Woodland Hills, CA). All rats were trained for 1 week prior to the beginning of the experiment in order to habituate them to this procedure. Blood pressures were measured daily throughout the duration of the study. Body weight was also measured daily throughout the course of the study.

At the conclusion of the treatment period, all animals were surgically prepared for assessment of renal hemodynamics and continuous measurement of arterial blood pressure as described previously. ${ }^{10}$ Briefly, the rats were anesthetized with pentobarbital sodium (50 $\mathrm{mg} / \mathrm{kg}$, intraperitoneal) and placed on a surgical table thermostatically controlled to maintain body temperature at $37^{\circ} \mathrm{C}$. A tracheostomy was performed, and the animals were allowed to breathe humidified air enriched with oxygen. The left jugular vein was cannulated to allow infusion of solutions and additional anesthetic. The rats were infused at a constant rate of 1.2 $\mathrm{mL} / \mathrm{h}$ with isotonic saline containing 6\% albumin (bovine; Sigma Chemical, St. Louis, MO) during surgery and thereafter with isotonic saline containing $1 \%$ albumin, $7.5 \%$ polyfructosan (Inutest; Fresenius Kabi Austria GmbH, Linz, Austria) and 1.5\% paminohippurate sodium (PAH; Merck Sharp \& Dohme, West Point, PA). The carotid artery was cannulated to allow measurement of arterial blood pressure. Blood pressure was monitored with a Statham pressure transducer (model P23DC) and recorded using a computerized data-acquisition system (MP100 System; BIOPAC Systems, Santa Barbara, CA) with the AcqKnowledge Software Package (version 3.7.3, BIOPAC). A suprapubic incision was made and the bladder was exposed by blunt dissection through the abdominal wall. The bladder was catheterized to allow timed urine collections to be made.

After a 45-minute recovery period, urine was collected during two 30-minute periods followed by a blood sample ( $\sim 3001)$ to allow assessment of whole kidney hemodynamics and excretory function. At the end of each experiment, both kidneys were removed, decapsulated, blotted dry, and weighed. Urine volume was determined gravimetrically. Sodium concentration in urine and plasma were measured using flame photometry. Inulin and PAH concentrations in both urine and plasma were measured by standard spectrophotometry. Glomerular filtration rate (GFR) and renal plasma flow (RPF) were estimated from the clearance of inulin and $\mathrm{PAH}$, respectively. Renal blood flow was calculated as RPF/( 1 - hematocrit). Renal vascular resistance (RVR) was determined from the quotient of mean arterial pressure (MAP) and calculated renal blood flow. 
Statistical analyses were performed within groups using one-way repeated measures ANOVA followed by Student-Newman-Keuls test and between groups using one-way ANOVA followed by Student-Newman-Keuls test. All statistical analyses were performed using SigmaPlot for Windows (version 11; Systat Software, San Jose, CA). Statistical significance was defined as $\mathrm{P}<0.05$. All data are expressed as mean \pm SEM.

\section{Results}

Conscious systolic blood pressures and changes in body weights of Cyp1a1-Ren2 transgenic rats are summarized in Figs. 1 and 2. Chronic administration of 0.15\% I3C resulted in an increase in SBP by day $3(130 \pm 7$ to $160 \pm 5 \mathrm{mmHg}, \mathrm{P}<0.01)$ and continued to increase incrementally to a peak of $191 \pm 6 \mathrm{mmHg}(\mathrm{P}<0.001)$ by day 16 (Figure 1$)$. The hypertensive animals did not exhibit signs of malignant hypertension, such as piloerection or severe lethargy. Hypertensive animals did not exhibit weight loss, but they did not experience a weight gain as seen in animals concurrently treated with aliskiren or maintained on a nonI3C diet (Figure 2). In this regard, noninduced rats increased their body weights by $14 \pm 1 \%$ $(\mathrm{P}<0.01)$, and induced rats treated chronically with aliskiren increased their body weights by $14 \pm 1 \%(\mathrm{P}<0.01)$ throughout the course of the study. In contrast, rat induced with $0.15 \%$ I3C maintained a constant body weight $(1 \pm 1 \%$, NS) throughout the course of the I3C induction. Chronic administration of the direct renin inhibitor, aliskiren, prevented the development of hypertension (113 \pm 5 vs. $114 \pm 5 \mathrm{mmHg}$, NS, Figure 1). Rats induced with $0.15 \% \mathrm{I} 3 \mathrm{C}$ had higher MAP than noninduced rats ( $201 \pm 6$ vs. $152 \pm 4 \mathrm{mmHg}, \mathrm{P}<0.001$, Figure 3 ). Rats treated chronically with aliskiren exhibited significantly lower MAP (138 \pm 4 vs. $201 \pm 6$ $\mathrm{mmHg}, \mathrm{P}<0.001$, Figure 3 ) compared with $0.15 \% \mathrm{I} 3 \mathrm{C}$ induced rats not treated chronically with aliskiren.

The effects of chronic treatment with aliskiren on renal hemodynamics and sodium excretory function in anesthetized animals are summarized in Figures 4-9. The rats induced with $0.15 \%$ I 3 C exhibited significantly lower GFR $(0.78 \pm 0.08$ vs. $1.18 \pm 0.11 \mathrm{ml} / \mathrm{min} . \mathrm{g}$, $\mathrm{P}<0.05$, Figure 4$)$ and RPF ( $2.56 \pm 0.21$ vs. $3.81 \pm 0.44 \mathrm{ml} / \mathrm{min} . \mathrm{g}, \mathrm{P}<0.05$, Figure 5$)$ than noninduced control rats. The hypertensive rats also exhibited elevated RVR ( $38 \pm 3$ vs. $22 \pm 2$ $\mathrm{mmHg} / \mathrm{ml} / \mathrm{min} . \mathrm{g}, \mathrm{P}<0.01$, Figure 6), urine flow ( $25.1 \pm 3.1$ vs. $15.9 \pm 2.5 \mu 1 / \mathrm{min}, \mathrm{P}<0.05$, Figure 7), absolute urinary sodium excretion ( $2.35 \pm 0.28$ vs. $1.22 \pm 0.38 \mu \mathrm{Eq} / \mathrm{min}, \mathrm{P}<0.05$, Figure 8$)$, and fractional sodium excretion $(0.96 \pm 0.25$ vs. $0.31 \pm 0.09 \%, P<0.05$, Figure 9$)$ compared with the noninduced control rats. Animals treated with aliskiren exhibited significantly higher GFR than induced rats not treated with aliskiren $(1.19 \pm 0.07 \mathrm{vs}$. $0.78 \pm 0.08 \mathrm{ml} / \mathrm{min} . \mathrm{g}, \mathrm{P}<0.01$, Figure 4). RPF in aliskiren treated rats similarly showed an increase when compared to the hypertensive animals $(4.22 \pm 0.23$ vs. $2.56 \pm 0.21 \mathrm{ml} / \mathrm{min} . \mathrm{g}$, $\mathrm{P}<0.01$, Figure 5). RVR ( $23 \pm 4$ vs. $38 \pm 3 \mathrm{mmHg} / \mathrm{ml} / \mathrm{min}$.g, $\mathrm{P}<0.01$, Figure 6 ), urine flow (17.6 \pm 1.5 vs. $25.1 \pm 3 \mu \mathrm{l} / \mathrm{min}, P<0.05$, Figure 7$)$, urinary sodium excretion ( $1.11 \pm 0.32$ vs. $2.35 \pm 0.28 \mu \mathrm{Eq} / \mathrm{min}, \mathrm{P}<0.05$, Figure 8$)$, and fractional sodium excretion $(0.96 \pm 0.25 \mathrm{vs}$. $0.35 \pm 0.10 \%, \mathrm{P}<0.05$, Figure 9) were all decreased in aliskiren treated rats when compared to hypertensive rats. Thus, chronic aliskiren treatment completely prevented any marked changes in renal hemodynamics and excretory function in I3C induced Cyp1a1-Ren2 rats.

\section{Discussion}

This study was performed to evaluate the effects of chronic direct renin inhibition with aliskiren on blood pressure and renal hemodynamics in Cyp1a1-Ren2 transgenic rats with inducible slowly progressive ANG II-dependent hypertension. Induction of the Ren2 renin gene by dietary administration of $0.15 \% \mathrm{I} 3 \mathrm{C}$ for 16 days resulted in the development of hypertension over course of the study. These changes in arterial blood pressure confirm previous findings that dietary administration of $0.15 \% \mathrm{I} 3 \mathrm{C}$ elicits slowly progressive ANG 
II-dependent hypertension in Cyp1a1-Ren2 transgenic rats. ${ }^{10}$ The hypertensive animals did not exhibit signs of malignant hypertension, such as weight loss, piloerection, and severe lethargy. Chronic aliskiren treated animals displayed no significant changes in systolic or mean arterial blood pressure throughout the 16 days of concomitant administration of the $0.15 \%$ I3C diet. Therefore, chronic direct renin inhibition with aliskiren effectively completely prevented the development of slowly progressive ANG II-dependent hypertension in Cyp1a1-Ren2 rats.

In the present study, the mean arterial blood pressures of the anesthetized rats were somewhat higher than the corresponding systolic blood pressures of the conscious rats. The reason for this discrepancy remains unclear, particularly as we previously demonstrated that conscious systolic blood pressures of Cyp1a1-Ren 2 rats induced with $0.15 \%$ I3C were higher than the corresponding mean arterial blood pressures of the anesthetized rats surgically prepared for renal clearance measurements. ${ }^{10}$ However, it is possible that a greater influence of the generally recognized effects of induction of anesthesia and the surgical stress induced in preparing anesthetized rats for renal clearance measurements to increase sympathetic tone and, thus, arterial blood pressure could account for the present finding that the mean arterial pressures of the anesthetized rats were somewhat higher than their corresponding conscious systolic blood pressures. In addition, in the present study, the conscious systolic blood pressures of the noninduced rats decreased over the course of the study (Fig. 1). It is possible that this decline in conscious systolic blood pressures occurred as a consequence of the rats becoming more acclimatized to having their blood pressures taken using tail-cuff plethysmography, even though these rats were trained to have their conscious blood pressures measured for one week prior to the initiation of the study. Regardless of the reason, it is clear that the noninduced rats did not exhibit increases in conscious systolic blood pressures throughout the course of the study.

Transgenic rats induced with $0.15 \% \mathrm{I}$ IC exhibited significantly decreased values for GFR and RPF and elevated RVR when compared to the noninduced group of animals. These findings are consistent with previous observations that low dose $(0.15 \%)$ I3C administration elicits slowly progressive hypertension associated with an increase in RVR and decreases in renal hemodynamic function. ${ }^{10}$ In addition, the data clearly demonstrate that pathophysiological increases in plasma renin activity and circulating ANG II levels that occur during the pathogenesis of slowly progressive hypertension elicit significant decreases in both RPF and GFR. These changes in renal hemodynamic function presumably occurred as a consequence of the direct pre- and postglomerular vasoconstrictor actions of ANG II generated as a consequence of I3C-induced expression of the Ren 2 renin gene. The current data also demonstrate that the ability of the preglomerular vasculature to prevent the transmission of the systemic hypertension to the glomerular capillaries remains intact after 16 days of $0.15 \% \mathrm{I} 3 \mathrm{C}$ induction. Transgenic rats induced with $0.15 \% \mathrm{I} 3 \mathrm{C}$ also displayed derangements in renal excretory function such as significant increases in urine flow, absolute urinary sodium excretion, and fractional excretion of sodium when compared to noninduced rats. However, in a previous study ${ }^{10}$, Cyp1a1-Ren2 rats induced with $0.15 \%$ I3C exhibited urinary sodium excretion rates that were not significantly different from those observed in noninduced control rats. The reason for the apparent discrepancy between those findings and the present observation that hypertensive Cyp1a1-Ren2 rats exhibited an almost two-fold increase in urinary sodium excretion is not readily apparent, but could be related to a shift to the right of the pressure natriuresis relation. Specifically, it is generally recognized that the pressure natriuresis relation is shifted to the right in ANG II-dependent hypertensive states such that higher arterial pressures are required to maintain normal rates of sodium excretion or elicit elevations in sodium excretion. Furthermore, despite being shifted to the right, the pressure natriuresis relation becomes steeper at higher levels of arterial blood pressure such that small increases in arterial pressure elicit large increases in sodium 
excretion. In this regard, the slightly higher mean arterial pressure $(201 \mathrm{mmHg})$ of the rats induced with $0.15 \% \mathrm{I} 3 \mathrm{C}$ in the present study would be expected to elicit a greater pressure natriuretic effect than the mean arterial pressure $(188 \mathrm{mmHg})$ of the Cyp1a1-Ren2 rats induced with $0.15 \% \mathrm{I} 3 \mathrm{C}$ in our previous study.$^{10}$ In essence, at such markedly elevated mean arterial blood pressures, small increases in the order of $10-12 \mathrm{mmHg}$ in mean arterial pressure could elicit pronounced pressure-dependent increases in urinary sodium excretion. Thus, the increases in urine flow and sodium excretion observed in the present study may reflect the pressure diuretic and natriuretic effects of the markedly elevated arterial blood pressure in the hypertensive rats. However, further studies are required to determine the specific mechanisms underlying the diuretic and natriuretic responses occurring during the pathogenesis of slowly progressive ANG II-dependent hypertension.

In a previous study, ${ }^{10}$ chronic candesartan treatment significantly increased urinary sodium excretion over 3-fold, whereas in the current study chronic aliskiren treatment had the opposite effect despite a similar ability of the two inhibitors to prevent the development of hypertension in Cyp1a1-Ren2 rats induced with I3C. The reason for this apparent discrepancy between the effects of $\mathrm{AT}_{1}$ receptor blockade by candesartan and renin inhibition by aliskiren is not clear but could relate to the disparate effects of the two inhibitors on the components of the renin-angiotensin system. Specifically, blockade of $\mathrm{AT}_{1}$ receptors with candesartan would block the effects of ANG II; however, it would not block the effects of ANG II to activate $\mathrm{AT}_{2}$ receptors. It is possible that the well-recognized diuretic and natriuretic effects of maintained $\mathrm{AT}_{2}$ receptor activation by the markedly elevated ANG II levels may have contributed to the elevated urinary sodium excretion previously observed during chronic $\mathrm{AT}_{1}$ receptor blockade with candesartan. ${ }^{10}$ In contrast, chronic administration of aliskiren would have inhibited renin activity and, thus, ANG II generation in Cyp1a1-Ren2 rats induced with $0.15 \%$ I3C. This would also have resulted in a diminished activation of $\mathrm{AT}_{2}$ receptors and, thereby, prevented $\mathrm{AT}_{2}$ receptor activation from eliciting diuretic and natriuretic effects, as observed in the present study.

Chronic treatment with aliskiren beginning four days prior to transgene induction prevented both the increase in arterial blood pressure and the associated derangements in renal hemodynamics. GFR and RPF were significantly higher in aliskiren treated animals when compared to induced rats not treated with aliskiren. RVR, urine flow, urinary sodium excretion, and fractional excretion of sodium were significantly lower in aliskiren treated animals when compared to the hypertensive animals. Indeed, values for GFR, RPF, RVR, urine flow, urinary sodium excretion, and fractional excretion of sodium in induced Cyp1a1Ren 2 rats chronically treated with aliskiren did not differ significantly from the respective values observed in the noninduced control animals. These data are consistent with previous findings that acute aliskiren administration normalizes the elevated arterial blood pressure and increases RPF in hypertensive Cyp1a1-Ren2 rats and that chronic aliskiren treatment reduces blood pressure and prevents the development of albuminuria in diabetic TGR(mRen2)27 rats. ${ }^{21,22}$

The ability of aliskiren to effectively prevent the development of hypertension and the associated renal functional derangements in Cyp1a1-Ren2 rats presumably occurred as a consequence of its ability to inhibit plasma renin activity, markedly reducing the generation of ANG I and ANG II and, thereby, preventing the hypertensinogenic mechanisms mediated by ANG II. However, aliskiren has also been shown to markedly suppress the gene expression of the (pro)renin receptor in glomeruli, tubules, and cortical vessels of diabetic TGR(mRen2)27 rats. ${ }^{22}$ In this regard, it has been hypothesized that renal (pro)renin receptor-mediated activation of prorenin and the subsequent increase in intrarenal ANG II formation may be neutralized by aliskiren and that this contributes, in part, to the renoprotective effect of aliskiren. ${ }^{22}$ Furthermore, the small molecular weight of aliskiren 
allows it to be filtered at the glomerulus, and indeed, aliskiren has been reported to concentrate within the glomeruli, arterioles, vasa recta, and distal nephron ${ }^{18,23}$. Part of the renoprotective effects of aliskiren may involve inhibition of intrarenal renin activity and reduction of intrarenal production of ANG II, as well as suppression of PRA and plasma ANG II levels. Whether such mechanisms contributed to the ability of aliskiren to prevent the development of the renal functional derangements in Cyp1a1-Ren2 transgenic rats induced with $0.15 \% \mathrm{I} 3 \mathrm{C}$ require further study.

It is worth noting that prorenin is markedly elevated in Cyp1a1-Ren2 rats with inducible ANG II-dependent hypertension. ${ }^{1}$ As most studies indicate that only prorenin binds to the prorenin receptor, it is possible that activation of the prorenin receptor by the elevated prorenin levels might contribute to the pathogenesis of the renal functional derangements in Cyp1a1-Ren2 rats with slowly progressive ANG II-dependent hypertension. However, given that $\mathrm{AT}_{1}$ receptor blockade similarly prevents the development of hypertension and the associated renal functional derangements ${ }^{10}$ as chronic renin inhibition with aliskiren, then this would argue against a significant role for prorenin-prorenin receptor interaction in mediating the hypertension and the associated renal functional derangements in Cyp1a1Ren2 rats with slowly progressive ANG II-dependent hypertension. Additional studies are required to address this issue.

In summary, the current data demonstrate that chronic direct renin inhibition with aliskiren prevents increases in MAP, RVR, urine flow, absolute urinary sodium excretion, and fractional sodium excretion and decreases in RPF and GFR in Cyp1a1-Ren2 transgenic rats induced with low dose $(0.15 \%)$ I3C. Therefore, the present findings demonstrate that chronic renin inhibition with aliskiren prevents the development of slowly progressive ANG II-dependent hypertension and the associated derangements in renal hemodynamics and excretory function in Cyp1a1-Ren2 transgenic rats. The data also show that renin generated as a consequence of expression of the Ren2 gene is responsible for the development of slowly progressive ANG II-dependent hypertension and the associated derangements in renal hemodynamics and excretory function in Cyp1a1-Ren2 transgenic rats.

\section{Acknowledgments}

The authors would like to thank Porcha D. Davis for excellent technical assistance. We also thank Dr. L. Gabriel Navar for helpful comments and suggestions, and Dr. Barb Mickelson, Harlan-Teklad, for help with the design and production of the $\mathrm{I} 3 \mathrm{C}$-containting rat diet.

This study was supported by the Tulane COBRE in Hypertension and Renal Biology (NCRR 2P20RR017659), by NHLBI grant HL26371, and by a grant from Novartis Pharmaceuticals Corp. (CSPP100A-US21T).

\section{References}

1. Kantachuvesiri S, Fleming S, Peters J, et al. Controlled hypertension, a transgenic toggle switch reveals differential mechanisms underlying vascular disease. J Biol Chem. 2001; 276:36727-36733. [PubMed: 11448960]

2. Campbell SJ, Carlotti F, Hall PA, et al. Regulation of the CYP1A1 promoter in transgenic mice: an exquisitely sensitive on-off system for cell specific gene regulation. J Cell Sci. 1996; 109:26192625. [PubMed: 8937980]

3. Forrester LM, Henderson CJ, Glancey MJ, et al. Relative expression of cytochrome P450 isoenzymes in human liver and association with the metabolism of drugs and xenobiotics. Biochem J. 1992; 281:359-368. [PubMed: 1736885]

4. Smith JD, Wong E, Ginsberg M. Cytochrome P450 1A1 promoter as a genetic switch for the regulatable and physiological expression of a plasma protein in transgenic mice. Proc Natl Acad Sci USA. 1995; 92:1926-11930. [PubMed: 7892201] 
5. Gelboin HV. Benzo[alpha]pyrene metabolism, activation and carcinogenesis: role and regulation of mixed-function oxidases and related enzymes. Physiol Rev. 1980; 60:1107-1166. [PubMed: 7001511]

6. Jellinck PH, Forkert PG, Riddick DS, et al. Ah receptor binding properties of indole carbinols and induction of hepatic estradiol hydroxylation. Biochem Pharmacol. 1993; 45:1129-1136. [PubMed: 8384853]

7. Loub WD, Wattenberg LW, Davis DW. Aryl hydrocarbon hydroxylase induction in rat tissues by naturally occurring indoles of cruciferous plants. J Natl Cancer Inst. 1975; 54:985-988. [PubMed: 1127728]

8. Pelkonen O, Nebert DW. Metabolism of polycyclic aromatic hydrocarbons: etiologic role in carcinogenesis. Pharmacol Rev. 1982; 34:189-222. [PubMed: 6287505]

9. Fujii-Kuriyama Y, Masatsuga E, Junsei M, et al. Polymorphic forms of the Ah receptor and induction of the CYP1A1 gene. Pharmacogenetics. 1995; 5:149-153.

10. Mitchell KD, Bagatell SJ, Miller CS, et al. Genetic clamping of renin gene expression induces hypertension and elevation of intrarenal Ang II levels of graded severity in Cyp1a1-Ren2 transgenic rats. J Renin Angiotensin Aldosterone Syst. 2006; 7(2):74-86. [PubMed: 17083061]

11. Howard LL, Patterson ME, Mullins JJ, et al. Salt-sensitive hypertension develops after transient induction of ANG II-dependent hypertension in Cyp1a1-Ren2 transgenic rats. Am J Physiol Renal Physiol. 2005; 228:F810-F815. [PubMed: 15585671]

12. Opay AL, Mouton CR, Mullins JJ, et al. Cyclooxygenase-2 inhibition normalizes arterial blood pressure in CYP1A1-REN2 transgenic rats with inducible ANG-dependent malignant hypertension. Am J Physiol Renal Physiol. 2006; 291:F612-F618. [PubMed: 16622181]

13. Graciano ML, Mouton CR, Patterson ME, et al. Renal vascular and tubulointerstitial inflammation and proliferation in Cyp1a1-Ren2 transgenic rats with inducible ANG II-dependent malignant hypertension. Am J Physiol Renal Physiol. 2007; 292:F1858-F1866. [PubMed: 17344186]

14. Williams DE, Prieto MC, Mullins JJ, et al. AT1 receptor blockade prevents the increase in blood pressure and the augmentation of intrarenal ANG II levels in hypertensive Cyp1a1-Ren2 transgenic rats fed with a high-salt diet. Am J Med Sci. 2010; 339:356-361. [PubMed: 20224314]

15. Milani CJ, Kobori H, Mullins JJ, et al. Enhanced urinary angiotensinogen excretion in Cyp1a1Ren2 transgenic rats with inducible ANG II-dependent malignant hypertension. Am J Med Sci. 2010; 340:389-394. [PubMed: 20724906]

16. Mitchell KD, Mullins JJ. Enhanced tubuloglomerular feedback in Cyp1a1-Ren2 transgenic rats with inducible ANG II-dependent malignant hypertension. Am J Physiol Renal Physiol. 2005; 289:F1210-F1216. [PubMed: 16033920]

17. Pilz B, Shagdarsuren E, Wellner M, et al. Aliskiren, a human renin inhibitor, ameliorates cardiac and renal damage in double-transgenic rats. Hypertension. 2005; 46:569-576. [PubMed: 16103264]

18. Feldman DL. New insights into the renoprotective actions of the renin inhibitor aliskiren in experimental renal disease. Hypertens Res. 2010; 33:279-287. [PubMed: 20203685]

19. Whaley-Connell A, Habibi J, Cooper SA, et al. Effect of renin inhibition and AT1R blockade on myocardial remodeling in the transgenic Ren2 rat. Am J Physiol Endocrinol Metab. 2008; 295:E103-E109. [PubMed: 18460596]

20. Rakusan D, Kujal P, Kramer HJ, et al. Persistent antihypertensive effect of aliskiren is accompanied by reduced proteinuria and normalization of glomerular area in Ren-2 transgenic rats. Am J Physiol Renal Physiol. 2010; 299:F758-F766. [PubMed: 20668096]

21. Howard CG, Mullins JJ, Mitchell KD. Direct Renin Inhibition With Aliskiren Normalizes Blood Pressure in Cyp1a1-Ren2 Transgenic Rats With Inducible Angiotensin II-Dependent Malignant Hypertension. Am J Med Sci. 2011; 341:383-387. [PubMed: 21358304]

22. Feldman DL, Jin L, Xuan H, et al. Effects of aliskiren on blood pressure, albuminuria, and (pro)renin receptor expression in diabetic TG(mRen-2)27 rats. Hypertension. 2008; 52:130-136. [PubMed: 18490518]

23. Feldman DL, Schuetz H, Persohn E, Muller DN. Light microscopy autoradiographic localization of the renin inhibitor aliskiren in rat kidneys [Abstract]. Hypertension. 56:e109. 2010b. 


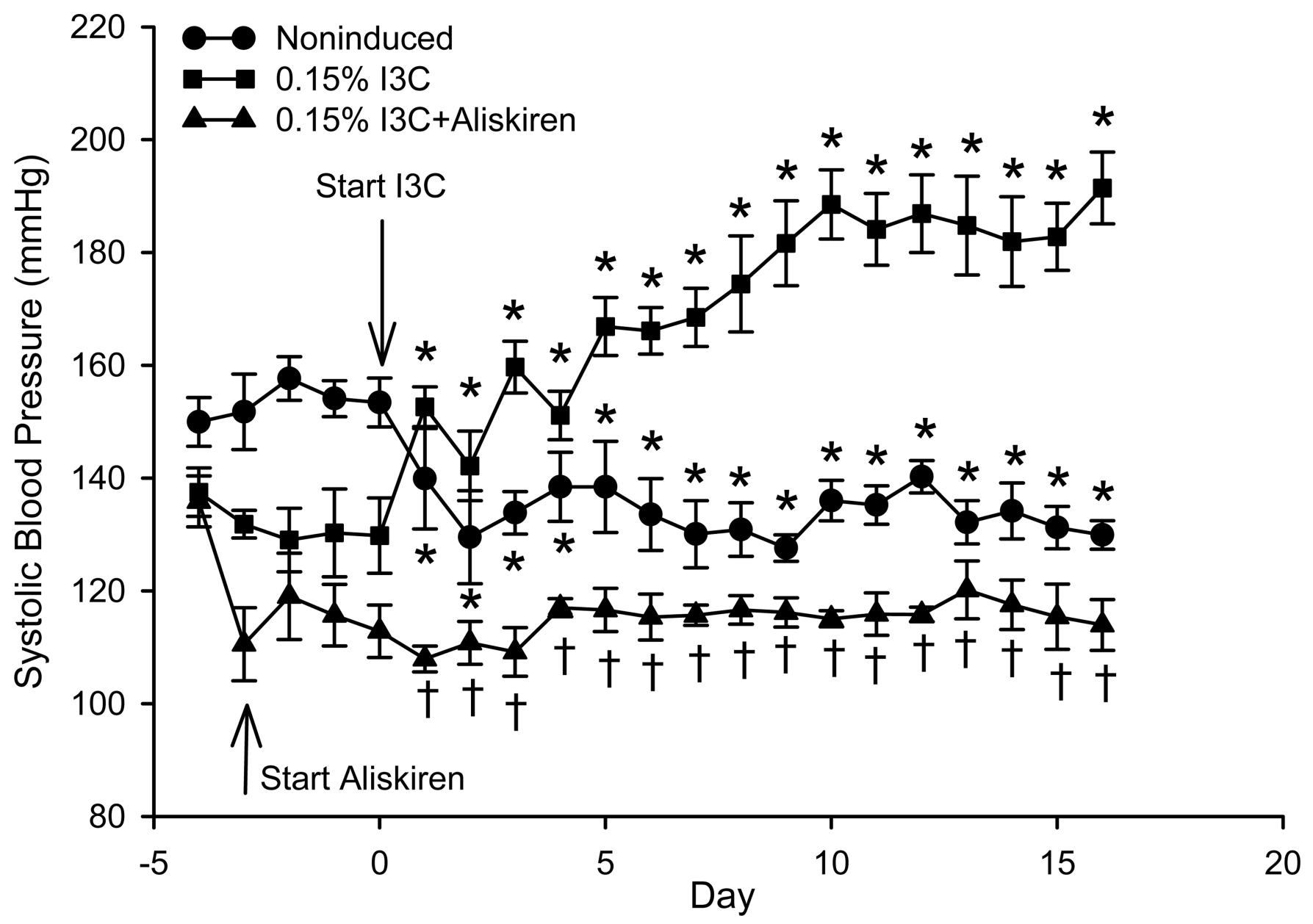

FIG. 1.

Conscious systolic blood pressures in noninduced (circle), $0.15 \%$ I3C-induced (square), and $0.15 \% \mathrm{I} 3 \mathrm{C}+$ aliskiren treated (triangle) Cyp1a1-Ren 2 rats. $* \mathrm{P}<0.05$ vs. day 0 within group. $\dagger \mathrm{P}<0.05$ vs. $0.15 \% \mathrm{I} 3 \mathrm{C}$-induced rats on corresponding day. 


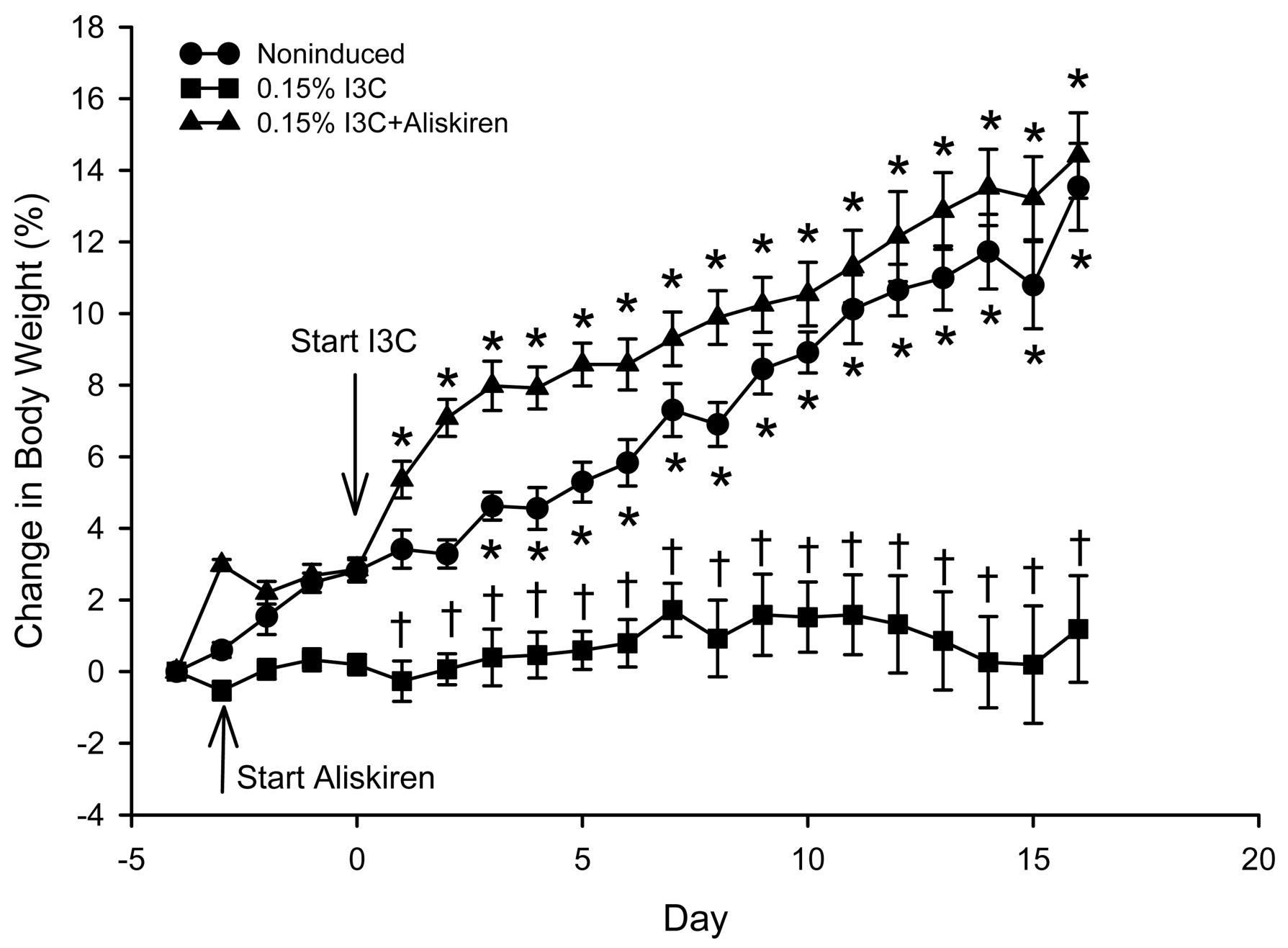

FIG. 2.

Change in body weight in noninduced (circle), $0.15 \%$ I3C-induced (square), and $0.15 \%$ I3C

+ aliskiren treated (triangle) Cyp1a1-Ren 2 rats. $* \mathrm{P}<0.05$ vs. day 0 within group. $\dagger \mathrm{P}<0.05$

vs. noninduced and $0.15 \%$ I3C-induced + aliskiren treated rats on corresponding day. 


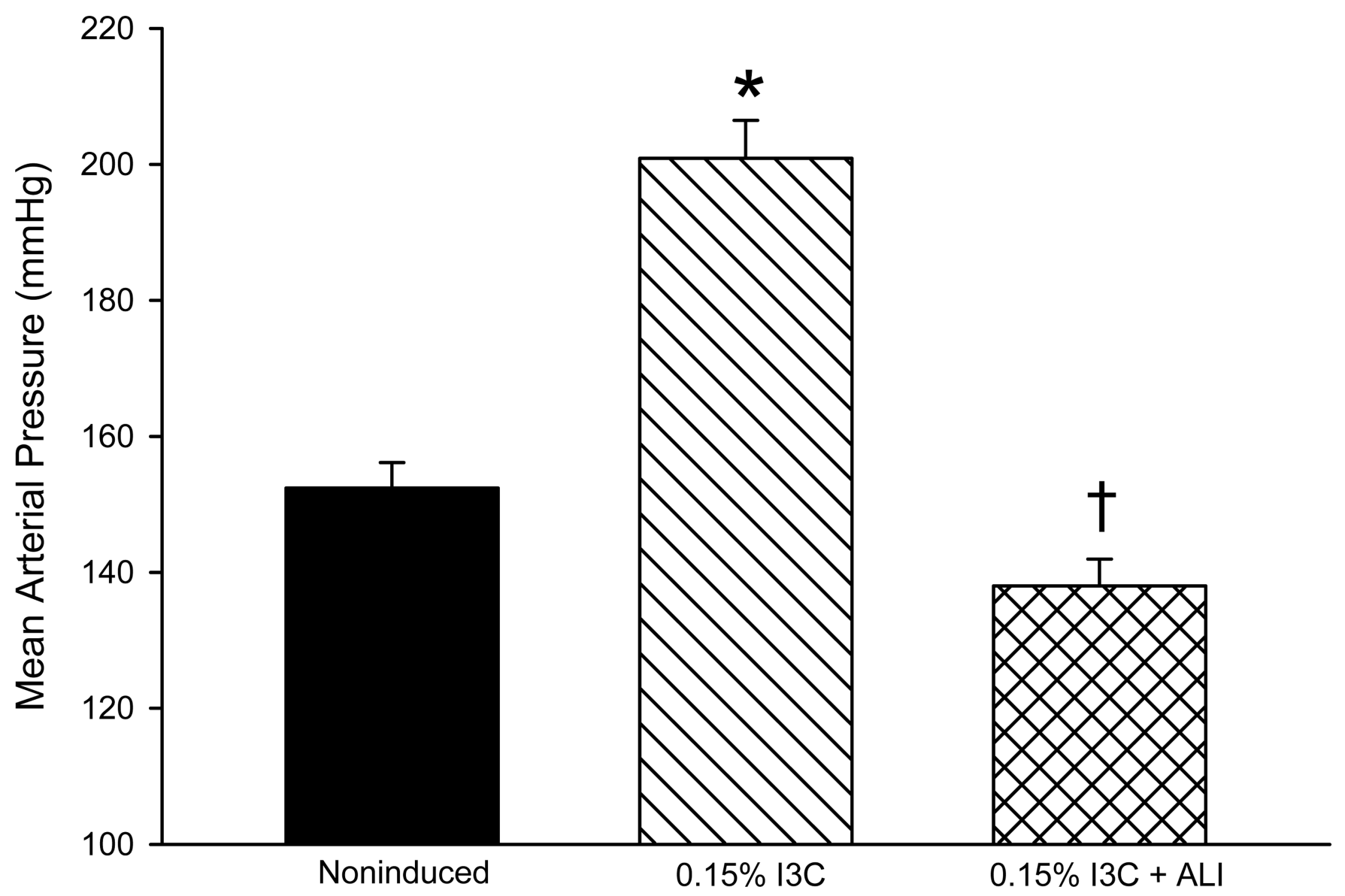

FIG. 3.

Mean arterial blood pressure in noninduced (solid bars), $0.15 \%$ I3C-induced (hatched bars), and $0.15 \% \mathrm{I} 3 \mathrm{C}+$ aliskiren treated (cross hatched bars) Cyp1a1-Ren 2 rats. ${ }^{*} \mathrm{P}<0.05$ vs. noninduced. $\dagger \mathrm{P}<0.05$ vs. $0.15 \%$ I3C-induced. 


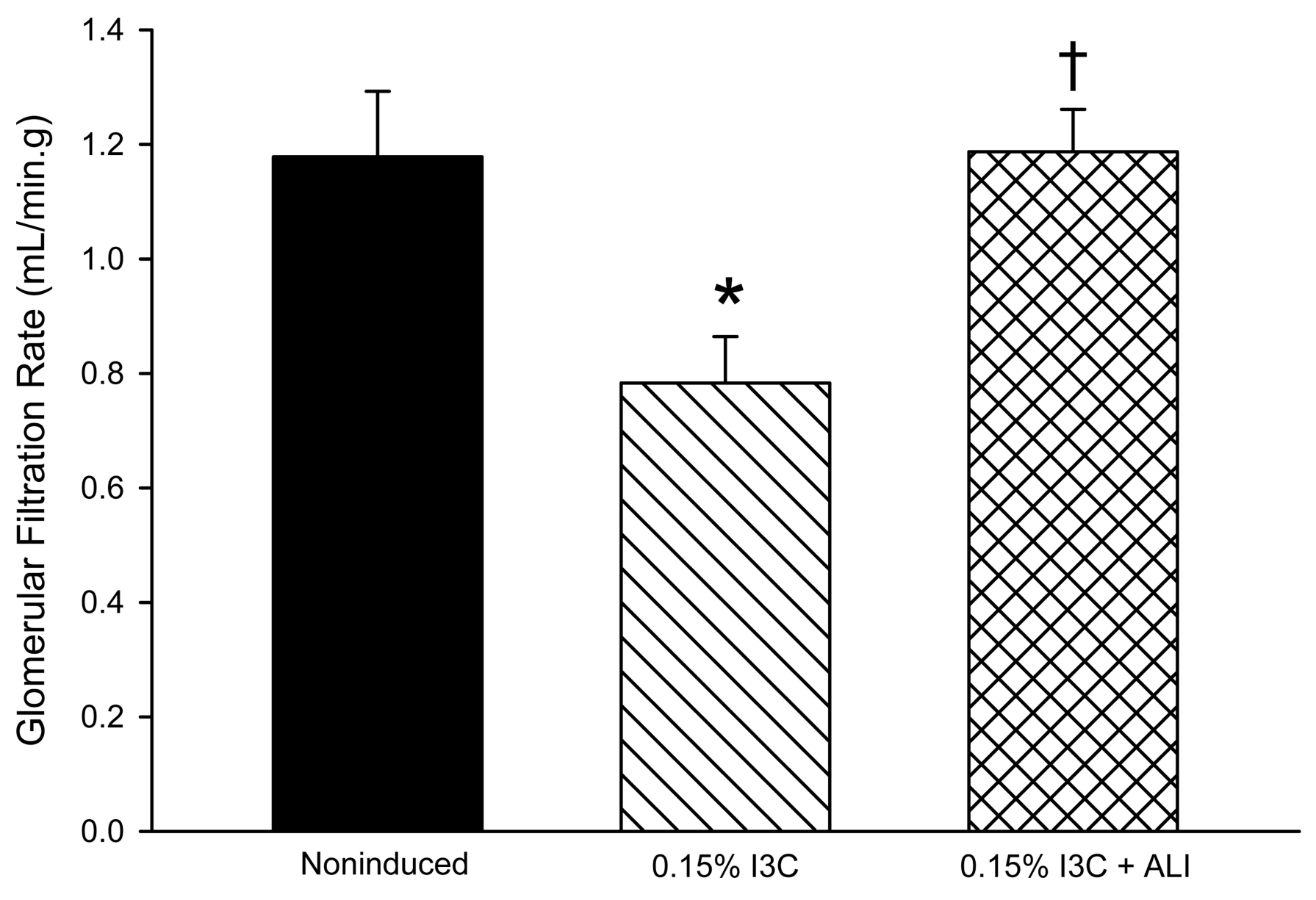

FIG. 4.

Glomerular filtration rate in noninduced (solid bars), $0.15 \%$ I3C-induced (hatched bars), and $0.15 \% \mathrm{I} 3 \mathrm{C}+$ aliskiren treated (cross hatched bars) Cyp1a1-Ren2 rats. $* \mathrm{P}<0.05$ vs. noninduced. $\dagger \mathrm{P}<0.05$ vs. $0.15 \% \mathrm{I}$ C-induced. 


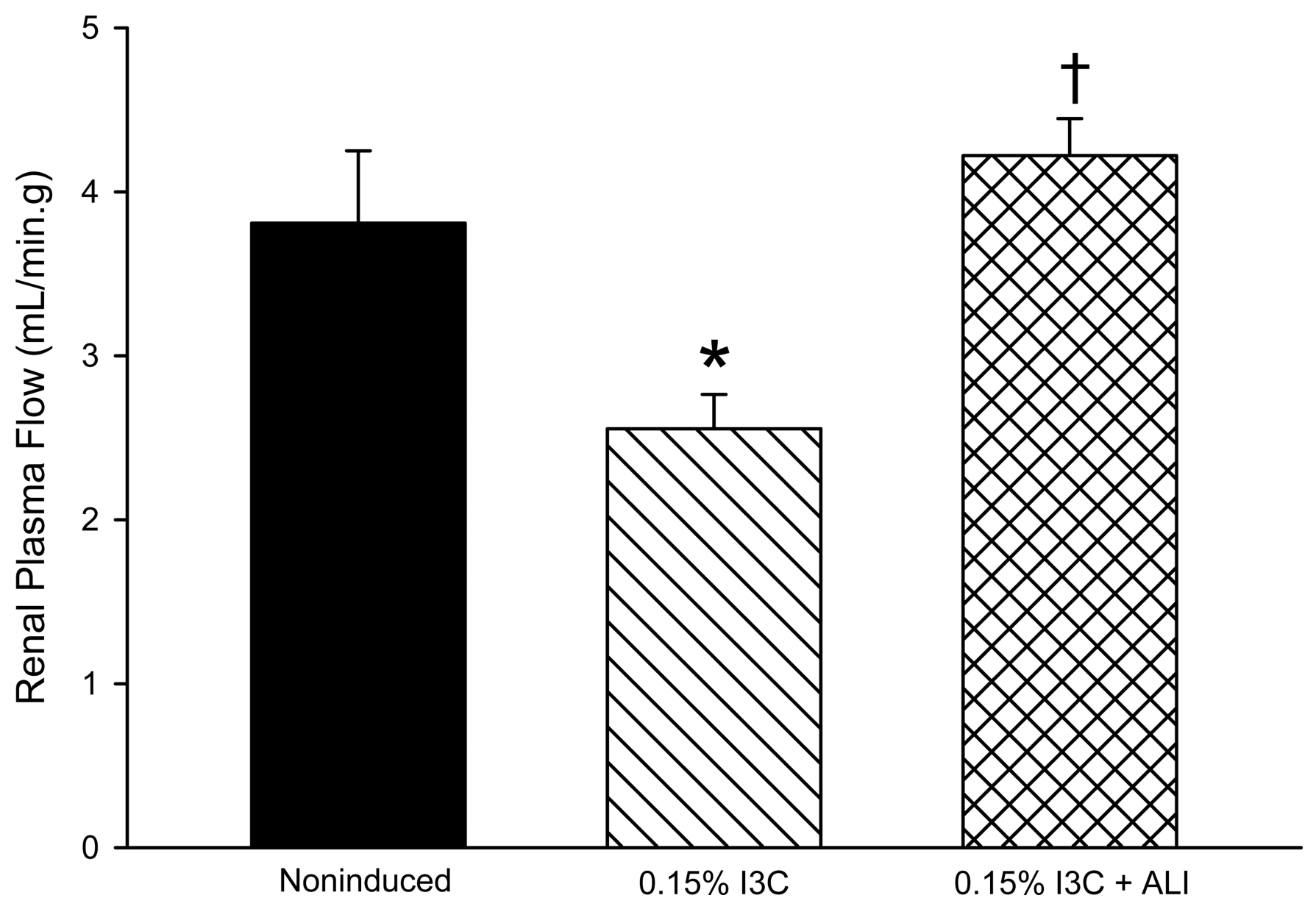

FIG. 5.

Renal plasma flow in noninduced (solid bars), $0.15 \%$ I3C-induced (hatched bars), and $0.15 \% \mathrm{I} 3 \mathrm{C}+$ aliskiren treated (cross hatched bars) Cyp1a1-Ren 2 rats. ${ }^{*} \mathrm{P}<0.05$ vs. noninduced. $\dagger \mathrm{P}<0.05$ vs. $0.15 \% \mathrm{I} 3 \mathrm{C}$-induced. 


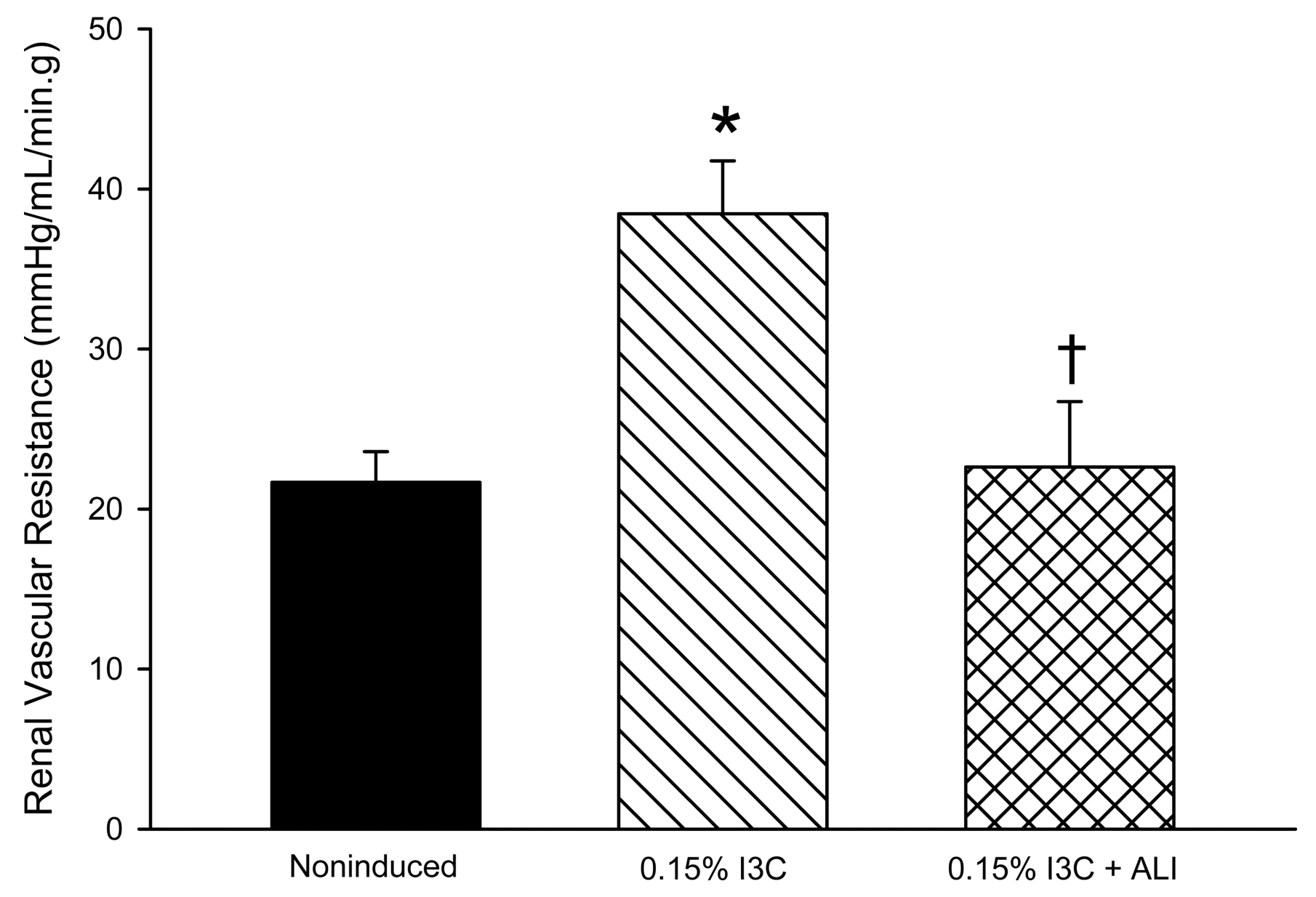

FIG. 6.

Renal vascular resistance in noninduced (solid bars), $0.15 \%$ I3C-induced (hatched bars), and $0.15 \% \mathrm{I} 3 \mathrm{C}+$ aliskiren treated (cross hatched bars) Cyp1a1-Ren2 rats. $* \mathrm{P}<0.05$ vs. noninduced. $\dagger \mathrm{P}<0.05$ vs. $0.15 \%$ I3C-induced. 


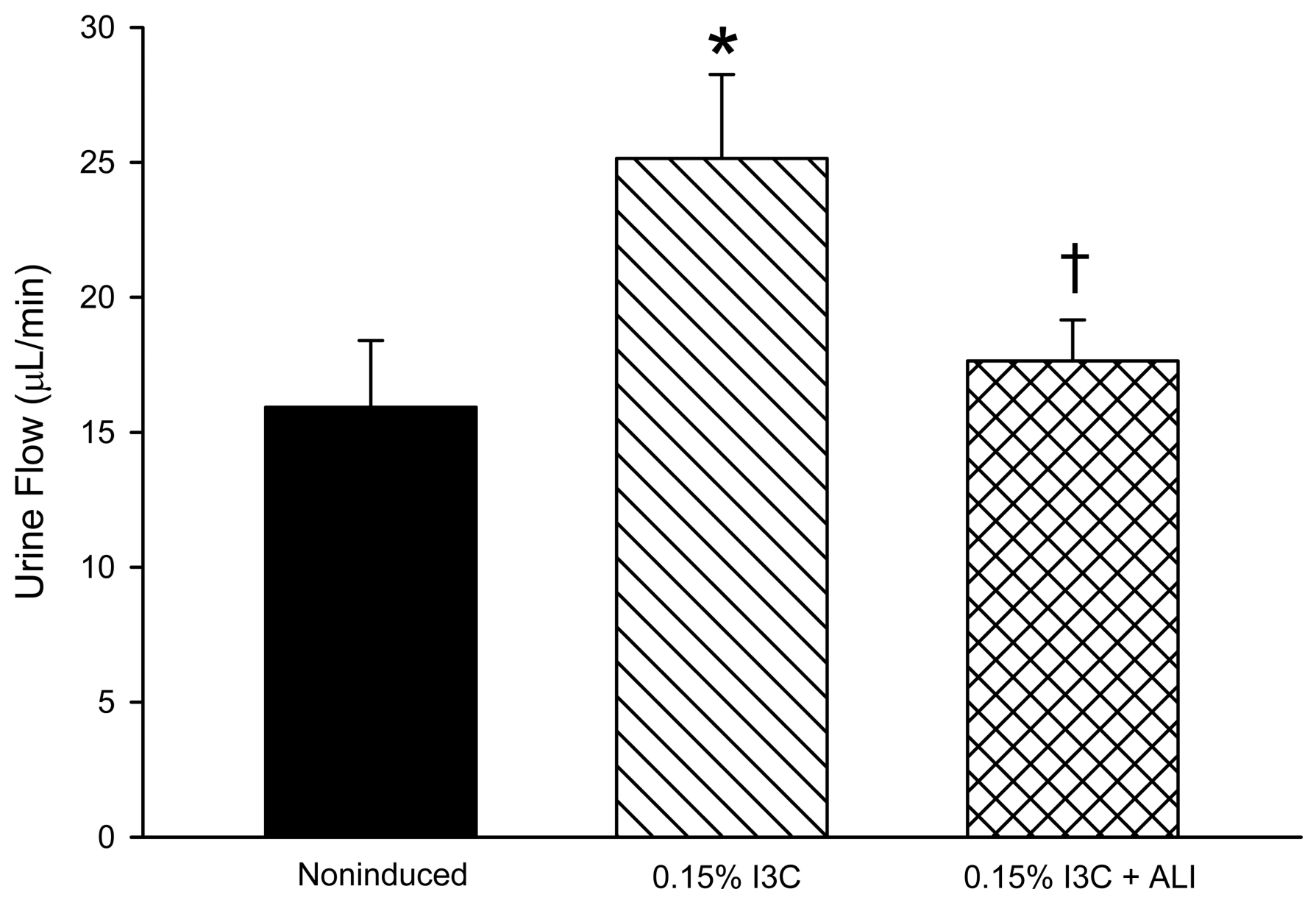

FIG. 7.

Urine flow in noninduced (solid bars), $0.15 \%$ I3C-induced (hatched bars), and $0.15 \% \mathrm{I} 3 \mathrm{C}+$ aliskiren treated (cross hatched bars) Cyp1a1-Ren2 rats. $* \mathrm{P}<0.05$ vs. noninduced. $\dagger \mathrm{P}<0.05$ vs. $0.15 \%$ I3C-induced. 


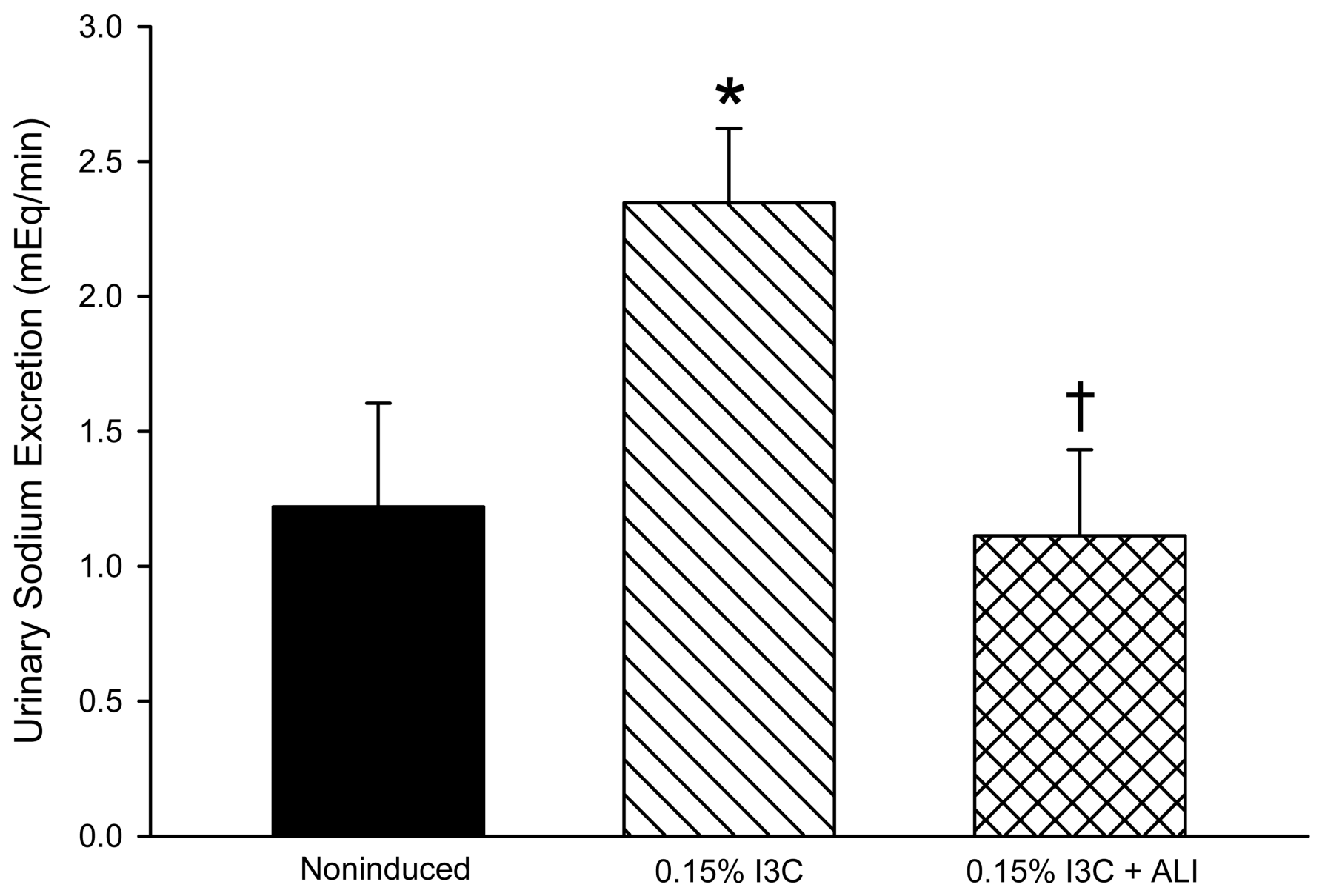

FIG. 8.

Urinary sodium excretion in noninduced (solid bars), 0.15\% I3C-induced (hatched bars), and $0.15 \% \mathrm{I} 3 \mathrm{C}+$ aliskiren treated (cross hatched bars) Cyp1a1-Ren 2 rats. $* \mathrm{P}<0.05$ vs. noninduced. $\dagger \mathrm{P}<0.05$ vs. $0.15 \%$ I3C-induced. 


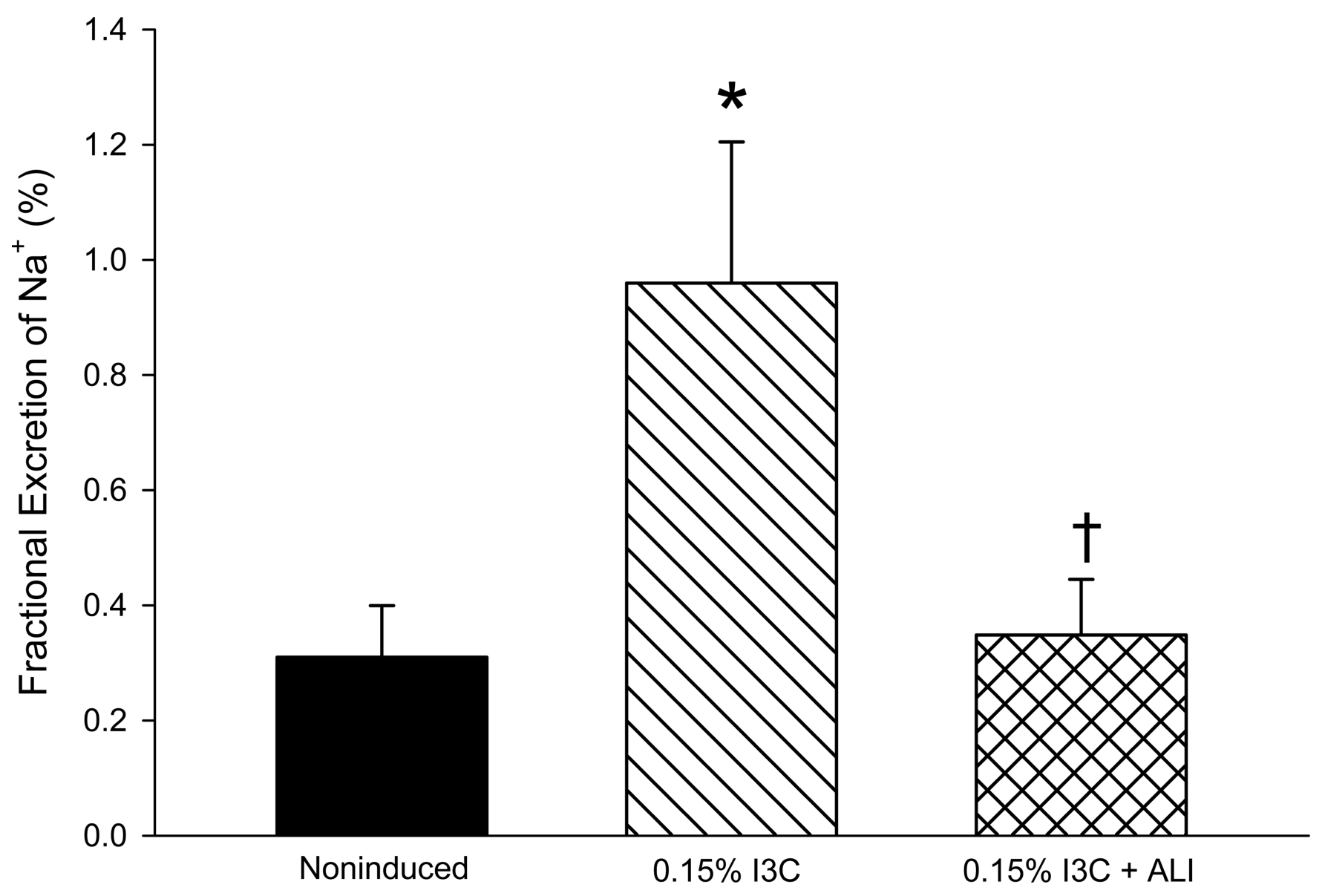

FIG. 9.

Fractional sodium excretion in noninduced (solid bars), $0.15 \%$ I3C-induced (hatched bars), and $0.15 \% \mathrm{I} 3 \mathrm{C}+$ aliskiren treated (cross hatched bars) Cyp1a1-Ren2 rats. ${ }^{*} \mathrm{P}<0.05$ vs. noninduced. $\dagger \mathrm{P}<0.05$ vs. $0.15 \%$ I3C-induced. 